\title{
ESR, CRP, and failure of Arterio-Venous Fistula (AVF)
}

\author{
Morteza Khavanin Zadeh ${ }^{1}$, Zahra Omrani ${ }^{2}$, Roozbeh Cheraghali ${ }^{3 *}\left(\mathbb{D}\right.$, Mehdi Hashemaghaee $^{4}$
}

Received: 23 Dec 2020

Published: 28 Sep 2021

\begin{abstract} checklist.

Keywords: ESR, CRP, Arteriovenous fistula (AVF), Failure

Conflicts of Interest: None declared

Funding: None

*This work has been published under CC BY-NC-SA 1.0 license.

Copyright $\odot$ Iran University of Medical Sciences
\end{abstract}

Background: The survival of arteriovenous fistula (AVF) remains an important problem for hemodialysis patients, accounting for $20 \%$ of all hospitalizations related to AV access problems in western countries. We designed an observational prospective cohort study on 265 AVFs and evaluated their results after 4 months of fistula creation and its relation to laboratory tests as ESR and CRP levels.

Methods: Wrist or antecubital AVFs were created for patients with End-Stage renal disease. All laboratory tests (ESR and CRP) were checked quantitatively. The patients were followed-upfor at least 4 months and failure or maturation of AVFs were recorded in a

Results: 177 (66.8\%) males and 88 (33.2\%) females were included. The surgeon created 161(60.8\%) wrist and 98 (37\%) antecubital AVFs. The mean age of patients was $53.18 \pm 17.1$, ranged from 8 to 91 years old. CRP and total protein had significant differences between the two groups of failure and mature accesses ( 0.029 and 0.045 respectively).

Conclusion: High CRP level is recognized as a reliable predictor for the survival of AVF.

Cite this article as: Khavanin Zadeh M, Omrani Z, Cheraghali R, Hashemaghaee M. ESR, CRP, and failure of Arterio-Venous Fistula (AVF). Med J Islam Repub Iran. 2021 (28 Sep);35:125. https://doi.org/10.47176/mjiri.35.125

\section{Introduction}

The increasing number of patients with chronic kidney disease (CKD) and End-Stage Renal Disease (ESRD) has become a major public health with large financial problems. Hemodialysis (HD), one of the methods of renal replacement therapy, depends on long-term patency of vascular access to allow adequate dialysis (1). In hemodialysis patients, a native arteriovenous fistula (AVF) is the preferred form of permanent vascular access and its dysfunction remains an important cause of morbidity in these patients (2).

The elderly (aged $>65$ years) account for an increasing number of ESRD patients initiating hemodialysis. In Europe, they represent $39 \%$ to $70 \%$ of patients, whereas in

\section{Corresponding author:Dr Roozbeh Cheraghali,Dr.r.Cheraghali@goums.ac.ir}

1. Hasheminejad Kidney Center, Iran University of Medical Sciences, Tehran, Iran

2. Rasool Akram Hospital, Iran University of Medical Sciences, Tehran, Iran

3. Vascular \& Endovascular Surgery, Golestan University of Medical Sciences, Gorgan, Iran

4ran University of Medical Sciences, Tehran, Iran the United States, the figure is $50 \%$. Two of Asia's largest hemodialysis populations also show a similar demographic trend: the mean age is 67.2 years in Japan, and $40 \%$ of Taiwanese ESRD incident patients are elderly (3).

The survival of arteriovenous fistula (AVF) remains an important problem for hemodialysis patients, accounting for about $20 \%$ of all hospitalizations related to AV access problems in western countries (4-6). The pathologic mechanisms of HD vascular access failure are multiple. Many risk factors such as diabetes, hypotension, insufficient surgical experience, a higher level of uremic toxin, and a decrease in heparin administration all had been documented to be related to the poor outcome of vascular

$\uparrow$ What is "already known” in this topic:

The presence of diabetes was independently related to primary AVF failure, possibly because diabetic patients were more likely to have increased thrombogenicity, impaired vasodilatation resulting from endothelial dysfunction and peripheral arterial disease.

$\rightarrow$ What this article adds:

We recommend checking CRP level before creating AVF. If CRP levels are elevated, it is better to postpone the creatation of AVF until normal CRP level. 
access (1).

The clinical risk factors associated with AV access failure are advanced age, diabetes mellitus, poor surgical technique, previous catheter insertion, and history of peripheral vascular diseases (7). The inflammatory process has been proposed to play a pathologic role in inflammatory markers including high-sensitivity $\mathrm{C}$ - reactive protein dysfunction and demonstrated that all these systemic inflammatory markers were elevated in patients with AVF dysfunction even though AVF is a local tissue (1). We designed an observational prospective cohort study on 265 AVFs and evaluated their results after 4 months of fistula creation and its relation to laboratory tests as ESR and CRP.

\section{Methods}

\section{Study population and design}

We conducted an observational prospective cohort study and enrolled 265 patients with ESRD on maintenance hemodialysis during a period of 3 years from 2016 to 2019 . A vascular surgeon made all wrist or antecubital AVFs at Hasheminejad Hospital,a referral center for ESRD patients, Tehran, Iran. The study was approved by Iran University of Medical Sciences ethics committee. To be included in the study, participants had to be at least 8 years old, receiving outpatient hemodialysis treatment thrice weekly in 3- to 4-hour sessions for at least 6 months. Patients were excluded if they were $<8$ years old, had a life expectancy of $<6$ months or if the first episode of AVF failure was related to an infectious complication, steal phenomenon or aneurysm.

Blood samples were obtained immediately before the surgery. All laboratory tests were performed by the hospital's central laboratory, and hs_CRP (high sensitive) was checked quantitatively. The surgeon followed the accesses for at least 4 months and failure or maturation of AVFs was recorded in a checklist. Other information of patients like age, sex, Body Mass Index (BMI), Diabetes, hypertension, hepatitis B, C, and Hemoglobin level were also recorded.

Diabetes mellitus (DM) was defined as patients who were receiving oral anti-diabetic or insulin treatment; with fasting blood sugar $\geq 126 \mathrm{mg} / \mathrm{dL}$ or random blood sugar $\geq 200 \mathrm{mg} / \mathrm{dL}$ with associated symptoms. Hypertension was defined as systolic blood pressure (SBP) over $140 \mathrm{~mm} \mathrm{Hg}$, diastolic blood pressure (DBP) over $90 \mathrm{~mm} \mathrm{Hg}$, or a history of the use of antihypertensive medications for lowering blood pressure. BMI was calculated as weight $(\mathrm{kg}) / \mathrm{height}$ $\left(\mathrm{m}^{2}\right)$.

\section{Definition of HD vascular access failure and combined endpoint}

The definition of HD vascular access failure was made clinically, based on the following criteria: the decrease or absence of palpable and audible bruit in patients with AVF, or clinical signs of AVF dysfunction (diminished thrill, limb swelling, decreased flow rate less than 150 $\mathrm{mL} / \mathrm{min}$ or increased venous pressure more than $200 \mathrm{~mm}$ $\mathrm{Hg}$ during HD) or the need for the placement of another new central venous catheter. We divided our follow-up into 3 groups: the first group access failure happened in 30 days, the second group during 30 to 120 days and the third group was patients with mature AVFs after 120 days.

\section{Statistical analysis}

Statistical analysis was computerized using the SPSS package for windows version 18.0 (SPSS Inc., Chicago, IL, USA). All continuous variables were provided for mean values \pm standard deviation (SD) or median (interquartile ranges), according to whether normal distribution as the Kolmogorov-Smirnov Z test. For the assessment of clinical features, biochemical factors, and access failure rate among three groups one-way analysis of variance (ANOVA), Kruskal-Wallis ANOVA, and chi-square test were applied between continuous and categorical variables, respectively. Also, unpaired tests and Fisher's tests were used to compare the differences between patients with diabetes or not. Logistic regression analysis was utilized to identify factors relevant to vascular access failure.

\section{Results}

Data of 265 patients were collected and analyzed by SPSS.177 (66.8\%) males and 88 (33.2\%) females were included. The surgeon created $161(60.8 \%)$ wrist and 98 (37\%) antecubital AVFs. The mean age of patients was $53.18 \pm 17.1$, ranged from 8 to 91 years old. Sixty percent of this population $(\mathrm{N}=159)$ had diabetes and $105(39.6 \%)$ were in the normal range. Information of the patients is listed in Table 1.

We compared the mean of quantitative variables as CRP, ESR, hemoglobin, lipid profile, liver enzymes, and coagulation tests by two independent sample T-Test (Table 2). Among these variables, CRP and total protein had a significant difference between the two groups of failure and mature accesses. (0.02 and 0.04 respectively )

We also recorded results of AVFs in 3 groups: group 1 was patients who had failure during the first 30 days of access creation. Group 2 was those who had a failure during 30-120 days, and the third group had matured AVF s after 4 months. Details of each group are listed in the Table 3 .

Using independent sample $\mathbb{T}$-test, there was no statistical difference between the mean of ESR and the status of AVFs (matured or functional) $(p=0.090)$ and the frequency of ESR positive patients didn't differ statistically between functional and failed AVFs $(p>0.05)$ but there was a statistical difference (ANOVA Post Hoc) between the mean of ESR in the 31-120 days failure group and matured group $(\mathrm{p}=0.043)$.

We evaluated the effect of age, sex, diabetes, hypertension, ESR and CRP on AVF maturation. There was a statistical difference between the mean of CRP in matured and failed AVFs ( $p=0.029)$.

\section{Discussion}

Eighty-seven (32.8\%) of the 265 AVFs had failure after 4 months and $178(67.2 \%)$ were matured and worked. CRP may be a common, reliable, and available inflammatory parameter. Patients with fluctuated CRP had the 
Table 1. Frequency of AVFs, diabetes, hypertension, smoking, and BMI

\begin{tabular}{|c|c|c|c|c|c|}
\hline Variable & & & Failure $(n=87)$ & Mature $(n=178)$ & $\mathrm{p}$ \\
\hline \multirow[t]{4}{*}{ AVF Site } & Wrist & & $48(55.2 \%)$ & $113(63.5 \%)$ & 0.187 \\
\hline & Ante cubital & & $37(42.5 \%)$ & $61(34.3 \%)$ & \\
\hline & Missing & & $2(2.3 \%)$ & $4(2.2 \%)$ & \\
\hline & Total & & $87(100 \%)$ & $178(100 \%)$ & \\
\hline \multirow[t]{4}{*}{ Hypertension } & Yes & & $57(65.5 \%)$ & $131(73.6 \%)$ & 0.152 \\
\hline & No & & $30(34.5 \%)$ & $46(25.8 \%)$ & \\
\hline & Missing & & 0 & $1(0.6 \%)$ & \\
\hline & Total & & $87(100 \%)$ & $178(100 \%)$ & \\
\hline \multirow[t]{4}{*}{ Diabetes } & Yes & & $34(39.1 \%)$ & $71(39.9 \%)$ & 0.872 \\
\hline & No & & $53(60.9 \%)$ & $106(59.6 \%)$ & \\
\hline & Missing & & 0 & $1(0.6 \%)$ & \\
\hline & Total & & $87(100 \%)$ & $178(100 \%)$ & \\
\hline \multirow[t]{8}{*}{ BMI } & $<18.5$ & & $4(4.6 \%)$ & $8(6.2 \%)$ & 0.944 \\
\hline & $18.5-24.9$ & & $36(41.4 \%)$ & $64(36 \%)$ & \\
\hline & $25-29.9$ & & $16(18.4 \%)$ & $32(18 \%)$ & \\
\hline & $30-34.9$ & & $8(9.2 \%)$ & $20(11.2 \%)$ & \\
\hline & $35-39.9$ & & $1(1.1 \%)$ & $3(1.7 \%)$ & \\
\hline & $>40$ & & 0 & $1(0.6 \%)$ & \\
\hline & Missing & & $22(25.3 \%)$ & $50(28.1 \%)$ & \\
\hline & Total & & $87(100 \%)$ & $178(100 \%)$ & \\
\hline \multirow[t]{4}{*}{ Smoke } & Yes & & $9(10.3 \%)$ & $22(12.4 \%)$ & 0.632 \\
\hline & No & & $78(89.7 \%)$ & $156(87.6 \%)$ & \\
\hline & Missing & & 0 & 0 & \\
\hline & Total & & $87(100 \%)$ & $178(100 \%)$ & \\
\hline Variable & Group & Mean & & Std. Deviation & $\mathrm{p}$ \\
\hline \multirow[t]{2}{*}{ CRP_mg/dL } & Failure & 24.47 & & 29.72 & 0.029 \\
\hline & Mature & 16.74 & & 25.44 & \\
\hline \multirow[t]{2}{*}{ ESR } & Failure & 58.90 & & 35.70 & 0.090 \\
\hline & Mature & 51.39 & & 30.69 & \\
\hline \multirow[t]{2}{*}{ Cholesterol } & Failure & 158.42 & & 46.39 & 0.873 \\
\hline & Mature & 157.32 & & 44.62 & \\
\hline \multirow[t]{2}{*}{ Triglyceride } & Failure & 138.03 & & 65.14 & 0.814 \\
\hline & Mature & 140.80 & & 83.89 & \\
\hline \multirow[t]{2}{*}{ HDL } & Failure & 40.18 & & 10.54 & 0.288 \\
\hline & Mature & 44.01 & & 27.59 & \\
\hline \multirow[t]{2}{*}{ LDL } & Failure & 92.34 & & 41.22 & 0.977 \\
\hline & Mature & 92.16 & & 37.87 & \\
\hline \multirow[t]{2}{*}{ AST } & Failure & 14.94 & & 5.63 & 0.313 \\
\hline & Mature & 16.97 & & 7.73 & \\
\hline \multirow[t]{2}{*}{ ALT } & Failure & 16.66 & & 11.91 & 0.873 \\
\hline & Mature & 16.21 & & 9.54 & \\
\hline \multirow[t]{2}{*}{ Total Protein } & Failure & 7.02 & & 1.58 & 0.045 \\
\hline & Mature & 6.42 & & 1.19 & \\
\hline \multirow[t]{2}{*}{ Albumin } & Failure & 3.59 & & 0.46 & 0.614 \\
\hline & Mature & 3.53 & & 0.81 & \\
\hline \multirow[t]{2}{*}{ Hemoglobin } & Failure & 9.36 & & 2.03 & 0.784 \\
\hline & Mature & 9.59 & & 7.45 & \\
\hline \multirow[t]{2}{*}{ Platelet } & Failure & 2.0 & & 84.3 & 0.395 \\
\hline & Mature & 2.1 & & 84.7 & \\
\hline
\end{tabular}

highest annual failure rate. The genetic background may lead to variation in response to inflammatory stimuli $(8$, 9).

Poy-Chaudhury was the first who found the role of inflammation, following invasive procedures such as angiography in AVF failure. The study demonstrated that intimal hyperplasia in anastomotic vessels is associated with thrombotic closure of AVFs, resulting in AVF failure (10).

In an article published in 2018 in China, they evaluated the CRP variability and risk of AVF thrombosis. The rate of annual vascular access failure was significantly higher in fluctuated CRP group (1).

Oana Stirbu, et. al in 2019 also got a similar result in which CRP level was an independent predictor of AVF patency loss (4).

In Another cohort study done in 2003, the association between single CRP measurement and mortality of peritoneal dialysis patients was evaluated and there was a statistical correlation (11)

We also checked CRP level before the access creation surgery and followed them for 4 months. A Canadian study on a large, multi-ethnic population compared arteriovenous fistula outcomes (AVF) among patients $<65$ years old (65- group) to those more than 65 years old $(65+$ group). Survival and use of interventions were similar among the young and old dialysis patients. Patients in the $65+$ group had an increased risk of fistula failure due to age (relative risk, RR 1.7; p=0.05) (12). But in our study, there was no difference in failure between patients young- 


\begin{tabular}{|c|c|c|c|c|c|c|}
\hline & & & \multicolumn{3}{|c|}{ Frequency } & Percent \\
\hline \multicolumn{3}{|c|}{ Early Failure $(<=30$ days $)$} & \multicolumn{2}{|c|}{18} & \multicolumn{2}{|r|}{6.8} \\
\hline \multicolumn{3}{|c|}{ Failure (31days-120days) } & \multicolumn{2}{|r|}{69} & \multicolumn{2}{|r|}{26.0} \\
\hline \multicolumn{3}{|c|}{ Maturation (after 120 days) } & \multicolumn{2}{|c|}{178} & \multicolumn{2}{|r|}{67.2} \\
\hline \multicolumn{3}{|c|}{ Total } & \multicolumn{2}{|c|}{265} & \multicolumn{2}{|r|}{100.0} \\
\hline \multicolumn{7}{|c|}{ Table 4. Logistic model to estimate the probability of AVF failure } \\
\hline Variable & $\mathrm{B}$ & S.E. & Wald & $\mathrm{df}$ & $\mathrm{p}$ & $\operatorname{Exp}(\mathrm{B})$ \\
\hline Hemoglobin & 0.001 & 0.024 & 0.003 & 1 & 0.95 & 1.0 \\
\hline Diabetes & -0.009 & 0.308 & 0.001 & 1 & 0.97 & 0.9 \\
\hline Age & 0.000 & 0.009 & 0.002 & 1 & 0.96 & 1.0 \\
\hline Gender & 0.091 & 0.301 & 0.091 & 1 & 0.76 & 1.0 \\
\hline Hypertension & 0.482 & 0.322 & 2.247 & 1 & 0.13 & 1.6 \\
\hline CRP_mg/dL & -0.014 & 0.005 & 7.003 & 1 & $<0.001$ & 0.9 \\
\hline $\operatorname{ESR}(+/-)$ & 0.076 & 0.395 & 0.037 & 1 & 0.84 & 1.0 \\
\hline Constant & 0.434 & 0.698 & 0.387 & 1 & 0.53 & 1.5 \\
\hline
\end{tabular}

er or older than 65 years (Pearson Chi-square: 0.6).

In our study there was no relationship between diabetic and non-diabetic patients regarding failure of AVFs. WeiHung Kuo et al. research, annual failure rate did not differ between diabetic and non-diabetic patients (1). In contrast, Afsar et al., demonstrated that the presence of diabetes was independently related to primary AVF failure, possibly because diabetic patients were more likely to have increased thrombogenicity, impaired vasodilatation resulting from endothelial dysfunction and peripheral arterial disease (13).

In our logistic Regression model, CRP was the only factor among sex, age, Hb, DM, HTN, ESR, CRP which affected AVF maturation.

According to the study by Tanushree Banerjee et Al. done in 2014 in the US, it is advisable to create AVF before CVC (central vein catheterization) as it makes inflammatory factors that affect the survival of AVFs (7). Higher levels of inflammatory mediators seen in CVC and AVG compared with AVF could potentially explain the higher mortality seen in patients with $\mathrm{CVC}$ and $\mathrm{AVG}$ compared with AVF (14).

This study has some limitations that deserve mention: we checked CRP just one time before surgery, and the range of CRP level may vary during the 4-month follow up. Occult inflammatory reactions such as periodontal disease or chronic Chlamydia pneumoniae infections might be ignored and not detected. Finally, we only evaluated the clinical factors related to AVF survival. Other important factors such as the status of native veins also may influence the patency of AVF.

\section{Conclusion}

High CRP level is recognized as a reliable predictor for survival of AVF. Larger studies are needed to get more reliable results.

\section{Acknowelegment \\ None declared}

\section{Conflict of Interests}

The authors declare that they have no competing interests.

\section{References}

1. Kuo WH, Lee YT, Ng HY, Wang CY, Wu CH, Lee CT. C-reactive protein variability is associated with vascular access outcome in hemodialysis patients. J Clin Lab Amal. 2018 Jan;32(1):e22213.

2. Bojakowski K, Dzabic M, Kurzejamska E, Styczynski G, Andziak P, Gaciong Z, et al. A high red blood cell distribution width predicts failure of arteriovenous fistula. PLoiS One. 2012;7(5):e36482.

3. Imai E, Horio M, Watanabe T, Iseki K, Yamagata K, Hara S, et al. Prevalence of chronic kidney dlisease in the Japanese general population. Clin Exp Nephrol. 2009; 13:621-630.

4. Stirbu O, Gadalean F, Viorel Piteal I, Ciobanu Gh, Schiller A, Grosu $\mathrm{J}$, et al. C-reactive protein as a prognostic risk factor for loss of arteriovenous fistula patency in hemodialyzed patients. J Vasc Surg. $2019 \mathrm{Jul} ; 70(1): 208-215$.

5. Ozdemir FN, Akcay A, Bilgic A, Akgul A, Arat Z, Haberal M. Effects of smoking and blood eosinophil count on the development of arteriovenous fistulae thrombosis in hemodialysis patients. Transplant Proc. 2005 Sep;37(7):2918-21

6. Moon JY, Lee HM, Lee SH, Lee TW, Ihm ChG, Jo YI, et al. Hyperphosphatemia is associated with patency loss of arteriovenous fistula after 1 year of hemodialysis. Kidney Res Clin Pract. 2015 Mar;34(1):41-46.

7. Banerjee T, Kim SJ, Astor B, Shafi T, Coresh J, Powe NR. Vascular access type, inflammatory markers, and mortality in incident hemodialysis patients: the Choices for Healthy Outcomes in Caring for End-Stage Renal Disease (CHOICE) Study. Am J Kidney Dis. 2014 Dec;64(6):954-61.

8. Pepys MB, Hirschfield GM. C- reactive protein: a critical update. J Clin Invest. 2003;111:1805-1812

9. Brull DJ, Serrano N, Zito F, Jones L, Montgomery HE, Romley A, et al. Human CRP gene polymorphism influences CRP levels: implications for the prediction and pathogenesis of coronary heart disease. Arterioscler Thromb Vasc Biol. 2003;23:2063-2069.

10. Roy-Chaudhury P, Arend L, Zhang J, Krishnamoorthy M, Wang Y, Banerjee R, et al. Neointimal hyperplasia in early arteriovenous fistula failure. Am J Kidney Dis. 2007 Now;50(5):782-90

11. Wang AYM, Woo J, Lam CWK, Wang M, Sea MMM, Lui SF, et al. Is a single time point $\mathrm{C}$-reactive protein predictive of outcome in peritoneal dialysis patients? J Am Sioc Nephrol. 2003 Jul;14(7):1871-9

12. Lok CE, Oliver MJ, Su J, Bhola C, Hannigan N, Jassal SV. Arteriovenous istula outcomes in the era of the elderly. dialysis population. Kidney Int. 2005;67:2462-2469.

13. Afsar B. The impact of inflammatory factors associated with primary arteriovenous failure. Int J Artif Organs. 2013;36:710-716

14. Dukkipati R, Molnar MZ, Park J, Jing J, Kovesdy CP, Kajani R, et al. Association of vascular access type with inflammatory marker levels in maintenance hemodialysis patients. Semin Dial. Jul-Aug 2014;27(4):415-23. 